\title{
Perceived Personal Control Buffers Terminal Decline in Well-Being
}

\author{
Denis Gerstorf \\ Humboldt University and German Institute for Economic \\ Research, Berlin, Germany \\ Nilam Ram \\ Pennsylvania State University and German Institute for \\ Economic Research, Berlin, Germany
}

\author{
Jutta Heckhausen \\ University of California, Irvine
}

Frank J. Infurna

Arizona State University

\section{Gert G. Wagner}

Max Planck Institute for Human Development, Berlin Germany and German Institute for Economic Research, Berlin, Germany

\author{
Jürgen Schupp \\ German Institute for Economic Research, Berlin, Germany and \\ Free University
}

\begin{abstract}
Recent research has repeatedly demonstrated that well-being typically evinces precipitous deterioration close to the end of life. However, the determinants of individual differences in these terminal declines are not well understood. In this study, we examine the role of perceived personal control as a potential buffer against steep terminal declines in well-being. We applied single- and multiphase growth models to up to 25-year longitudinal data from 1,641 now-deceased participants of the national German Socio-Economic Panel Study (SOEP; age at death: $M=74$ years; $S D=14 ; 49 \%$ women). Results revealed that perceiving more personal control over one's life was related to subsequently higher late-life well-being, less severe rates of late-life declines, and a later onset of terminal decline. Associations were independent of key predictors of mortality, including age, gender, SES, and disability. These findings suggest that feeling in control may ameliorate steep end-of-life decline in well-being. We also discuss scenarios for when and how processes of goal disengagement and giving up control may become beneficial.
\end{abstract}

Keywords: control perceptions, control strivings, differential aging, German Socio-Economic Panel Study, mortality, multiphase growth model, SOEP, successful aging

A central objective of life span research is to describe and explain individual differences in intraindividual changes in major domains of functioning (Baltes \& Nesselroade, 1979). One of the most intriguing phenomena in this regard is terminal decline (i.e., rapid deteriorations in the last years of life) in crucial areas of

Denis Gerstorf, Humboldt University, Berlin, Germany and German Institute for Economic Research, Berlin, Germany; Jutta Heckhausen, Department of Psychology and Social Behavior, University of California, Irvine; Nilam Ram, Department of Human Development and Family Studies, Pennsylvania State University and German Institute for Economic Research; Frank J. Infurna, Department of Psychology, Arizona State University; Jürgen Schupp, German Institute for Economic Research and Department of Political and Social Sciences, Free University, Berlin, Germany; Gert G. Wagner, Max Planck Institute for Human Development, Berlin, Germany and German Institute for Economic Research.

The authors gratefully acknowledge the support provided by the National Institute on Aging Grants RC1-AG035645, R21-AG032379, and R21-AG033109; the Max Planck Institute for Human Development, Berlin; and the Penn State Children, Youth, and Families Consortium. The content is solely the responsibility of the authors and does not necessarily represent the official views of the funding agencies.

Correspondence concerning this article should be addressed to Denis Gerstorf, Humboldt University Berlin, Institute of Psychology, Rudower Chaussee 18, 12489 Berlin, Germany. E-mail: denis.gerstorf@hu-berlin.de functioning, including well-being (Berg et al., 2011; Diehr et al., 2002; Gerstorf, Ram, Estabrook et al., 2008; Gerstorf, Ram, Röcke et al., 2008; Gerstorf, Ram, Mayraz et al., 2010; Palgi et al., 2010; Schilling et al., 2012; Vogel et al., 2012). Although there is substantial heterogeneity in individuals' terminal trajectories, the specific factors contributing to those differences are poorly understood (for overview, see Gerstorf \& Ram, 2013). In this study, we examine the role of perceived control as a moderator of terminal decline in well-being. To do so, we apply single- and multiphase growth models to 25-year longitudinal data from 1,641 now deceased participants in the nation-wide German Socio-Economic Panel (SOEP; age at death: $M=74$ years; $S D=14 ; 49 \%$ women). We examine whether and to what extent perceived personal control is associated with late-life well-being, rates of terminal decline, and later onset of such declines.

\section{Well-Being Trajectories in Adulthood and Old Age}

Consistent with theories of self-regulation (Brandstädter, 1999; Brickman \& Campbell, 1971; Carstensen, 2006), a myriad of cross-sectional and longitudinal studies report that average levels of well-being remain relatively stable across adulthood and old age (Charles et al., 2001; Costa et al., 1987; Diener et al., 2006; Diener \& Suh, 1998; Kunzmann et al., 2000; Mroczek \& Kolarz, 1998). The evidence is largely consistent across the various different 
facets of well-being, including its cognitive-evaluative components (e.g., satisfaction with life overall or with particular domains, such as health and family) and affective-emotional components (e.g., positive affect, negative affect, and depressive symptoms). Researchers have referred to this pattern of findings as the "wellbeing paradox of old age" because the stability in well-being appears to defy often observed major changes in terms of developmental gains and particularly losses in old age (Baltes, \& Baltes, 1990; Brandtstädter \& Greve, 1994: Filipp, 1996). These findings conjointly suggest that the self-regulation system is highly efficient in helping people adapt to a variety of (changes in) life circumstances. In contrast to the stability in adulthood and old age, studies over the past 10 years targeting late-life well-being are challenging the prevailing view that well-being remains stable and positive throughout the adult life span. When comparing individuals who had subsequently died over a given study interval with those who survived, the nonsurvivors were found to have reported considerably lower well-being than the survivors, even after the usual mortality predictors such as chronological age, education, health, and cognitive abilities were taken into account (Danner et al., 2001; Levy et al., 2002; Maier \& Smith, 1999). Moreover, evidence is mounting that well-being typically shows steep declines at the end of life (i.e., terminal decline; Berg et al., 2011; Diehr et al., 2002; Palgi et al., 2010; Schilling et al., 2012). For example, Mroczek and Spiro (2005) reported that men from the Normative Aging Study who died within one year after assessment showed steeper age-related decline in life satisfaction between ages 50 and 80 than those who did not die. In line with notions of terminal decline (Birren \& Cunningham, 1985; Kleemeier, 1962), evidence suggests that mortality-related processes rise to the surface (of consciousness) as people approach death and become the primary force underlying well-being change. Indeed, average wellbeing appears to follow a multiphase trajectory with a preterminal phase of relative stability (that mirrors age-related change) transitioning into a terminal phase of rapid decline. For example, using data from deceased participants in national studies in the United States, Great Britain, and Germany, Gerstorf, Ram, Mayraz, and colleagues (2010) located the typical onset of such pronounced declines in well-being within a time window occurring between three and five years prior to death. The typical German participant experienced almost a full standard deviation of well-being decline in the last four years of life.

Despite this typical trajectory of seemingly inevitable late-life decline in well-being, vast individual differences exist in how people experience their last years of life (for review, see Gerstorf \& Ram, 2013). To begin with, some people report relatively high well-being in close proximity to death, whereas others report impoverished well-being late in life. Second, some people are able to maintain relatively high well-being into very late life, whereas others take a precipitous fall as they approach death. Third, individuals differ in the timing of the transition into terminal decline. In one of the rare investigations based on sufficiently extensive within-person change data (12+ annual data points per person), Gerstorf, Ram, Estabrook, and colleagues (2008) were able to estimate individual differences in the onset of terminal decline. As expected, individuals, on average, transitioned into the terminal phase at roughly four years before death. However, some individuals entered as early as six or eight years before death, others entered as late as two years prior, and still others did not show- even in old and very old age-any evidence of ever entering the terminal phase at all. Taken together, there are huge individual differences in levels of late-life well-being as well as in the rate and the onset of terminal decline in well-being.

We are only at the very beginning of understanding the factors that contribute to such individual differences. In empirical studies, we often find that established predictors of well-being and mortality (including age, gender, comorbidities, dementia, and cognition) account for only small portions of individual differences in terminal decline (Gerstorf \& Ram, 2013). One of the very few exceptions is very old age, with people surviving to an older age at death often entering the terminal decline phase relatively earlier and showing steeper declines afterward (Gerstorf, Ram, Estabrook et al., 2008). Other exceptions are proxies of pathologies (e.g., disability: Gerstorf, Ram et al., 2013; comorbidities: Gerstorf, Ram, Röcke et al., 2008; prolonged illnesses such as cardiovascular disease, cancer, and respiratory disease: Infurna et al., 2013) that have been found to be associated with lower levels of late-life functioning. To date, however, research has not identified psychological characteristics that predict vulnerability for and resilience against terminal well-being decline. In the current study, we test the hypothesis that individual differences in end-of-life well-being reflect critical differences in the adaptiveness of individuals' selfregulation. Specifically, we hypothesize that individuals who perceive themselves as actively and successfully pursuing control over their own life and development (as a key indicator of selfregulatory capabilities) are less likely to experience as severe a decline in well-being during the years immediately preceding their death.

\section{Control Beliefs as Predictors of Successful Aging}

Perceptions of control refer to beliefs about one's capacity to bring about a given outcome (Krause, 2003; Lachman \& Weaver, 1998; Levenson, 1981). Such perceptions of effectiveness and mastery are generally considered essential predictors of successful aging, with numerous studies showing consistently close associations with key indicators of adaptation (Baltes \& Baltes, 1990; Lachman \& Weaver, 1998; Rowe \& Kahn, 1997; Ryff \& Singer, 1998). To illustrate, various facets of perceived control including self-efficacy, striving for control, mastery, and control beliefs have been identified as protective factors against substantial health decrements (Caplan \& Schooler, 2003; Femia et al., 1997; Hall et al., 2010; Infurna, Gerstorf, \& Zarit, 2011; Mendes de Leon et al., 1996; Seeman et al., 1999) and as predictors of a longer life (Infurna et al., 2011; Krause \& Shaw, 2000; Penninx et al., 1997; Surtees et al., 2006, 2010). Numerous pathways have been suggested to underlie such links (Heckhausen et al., 2010; Lachman, 2006; Rodin, 1986; Skaff, 2007; Uchino, 2006). Specifically, perceived control is known to be linked with health-promoting behaviors (Lachman \& Firth, 2004; White, Wójcicki, \& McAuley, 2012), to buffer the impact of stressors on physiological reactivity (Kunz-Ebrecht et al., 2004; Neupert et al., 2007), to help downregulate negative emotions (Hay \& Diehl, 2010), to activate opportunity-congruent primary and secondary strategies (Hall et al., 2010), and to mobilize social support in times of strain that may serve as a stress buffer (Antonucci, 2001; Cohen \& Wills, 1985). Each of these factors can in turn be expected to foster well-being. 


\section{Control and Late-Life Well-Being Trajectories}

Our overarching hypothesis is that perceived personal control remains an important resource into late life which helps people maintain behavioral and physiological functions as long as possible (Rodin, 1986; Seeman et al., 1999). Specifically, we argue that successful development and aging can be conceptualized as making the most of the prevalent opportunities of control at any time during life and across the major changes in control potential across the life span. Very late in life when control potential in several areas of functioning may be severely constrained, it is particularly essential for the individual to selectively focus on the remaining control opportunities (e.g., to maintain close relations to the most cherished social partners; Heckhausen et al., 2010). Making the most of the remaining control potential should help older adults to both stave off functional decline and maintain a reasonably high level of well-being. In contrast, perceiving a lack of control may act as a dysregulating signal, which increases exposure to or the intensity of the maladaptive and disruptive mechanisms that accelerate functional decline and pathology. For example, impaired control of stressors can alter physiological functioning such as dysregulation of the HPA axis and increase the risk for diseases (Cohen, 2000; Juster, McEwen, \& Lupien, 2010) and accompanying well-being decline.

Taken together, we propose that perceived personal control serves as a general-purpose mechanism that supports individuals' regulatory capacities, especially during a time of life when the burdens of impending death begin to "overwhelm" a limited pool of resources. Regulatory capacity should in turn positively affect late-life quality of life and well-being. More specifically, perceived control may serve a protective role for well-being and shape its late-life trajectory in three different ways. To begin with, perceived control would bolster the hopefulness and be associated with more efficient adaptive strategies, which in turn would relate to higher overall levels of well-being. For example, a person with disability-related constrained mobility might focus his or her energy and time on keeping up a competitive edge in online chess. Second, perceived control would have beneficial effects on the objective declines in functioning, thereby postponing the onset of terminal decline. For example, perceived control allows older adults approaching death to utilize and make the best out of remaining capabilities. Such focused investment in maintaining control over cherished areas of functioning can help preserve one's capabilities in select areas as long as possible. Finally, perceived control might enhance self-protective interpretive processes (e.g., by way of boosting hopefulness, self-esteem, or contingency beliefs), which would moderate the slope of decline with which well-being reflects objective declines in functioning.

\section{The Present Study}

Taken together, research shows that late-life changes in wellbeing are marked by terminal decline. Our study is (among) the first to examine whether and how control perceptions alleviate such declines. To do so, we apply single- and multiphase growth models to up to 25-year longitudinal data from 1,641 now deceased participants in the nationwide SOEP study. The measure of perceived personal control available for our archival data analysis encompasses items that represent global dispositional beliefs and attitudes about the control a given participant exerts over a typical situation in his or her life. Based on the facilitative nature of control for processes of adaptation, we expect that perceived control is associated with higher late-life well-being, shallower rates of decline, and a later onset of such terminal well-being declines. To control for known correlates of mortality, perceived control, and well-being, all our models covary for age at death, gender, education, and disability, and the time elapsed between assessment of perceived control and participant death.

\section{Method}

To examine our research questions, we used 25 years of longitudinal data obtained from decedents in the SOEP (Headey et al., 2010). Comprehensive information about this household panel study - that is increasingly used in psychological research-is reported in Wagner et al. (2007).

\section{Participants and Procedure}

The SOEP is a nationally representative national panel study of private households covering $\sim 50,000$ residents of Germany, including immigrants and resident foreigners. Potential participants were drawn at random from a set of randomly selected geographic locations in Germany. Relatively high initial response rates (between $60 \%$ and $70 \%$ ) and low longitudinal attrition (about $15 \%$ for the second wave and less than $5 \%$ yearly attrition across various subsamples) provide for an overall sample that is representative of the population living in private households (Kroh \& Spieß, 2006; Kroh et al., 2008) and long-term care homes in Germany (Klein, 1996). Data are collected annually and primarily via face-to-face interviews, with the exception that about $10 \%$ of individuals who had already participated several times provided data via selfadministered mail questionnaires.

With an interest in end-of-life processes, we make use of the SOEPs continuous tracking of participants through to their deaths. Mortality status and month of death for deceased participants is obtained at the yearly interviews, either directly from the remaining household members or neighbors or from official registries. In total, the death rates and ages of death of SOEP participants parallel official life tables and serve as a representative resource for mortality-related analyses in Germany (e.g., Brockmann \& Klein, 2004; Burkhauser et al., 2005). For the current report, we used data obtained from the 1,641 participants who had (a) died before May 2009, (b) provided at least one rating of well-being during the last 10 years of their lives, and (c) provided data on perceived control and all covariates.

These decedents were born between 1897 and 1979 and died between 19 and 101 years later (average age at death $=73.55$, $S D=14.04$, median $=76$, mode $=81$, sometime between 1994 (the year in which perceived control were assessed first) and 2009 (13 years after which the current perceived control items were assessed last). Based on evidence that terminal well-being decline generalizes to deaths that occur across the entire adult life span rather than just in old age (Gerstorf, Ram, Mayraz et al., 2010;), we decided to include into our analyses all by now deceased SOEP participants independent of their age (i.e., also the $7 \%$ who died before age 50). As expected, when compared with still living participants, our current deceased subsample was on average, older at $\mathrm{T} 1, M=58.67$ years, $S D=13.96$ versus $M=39.28, S D=$ 
18.11, $F(1,43,314)=1,837.04, p<.001, R^{2}=.041, d=1.08 ;$ reported lower levels of well-being, $M=6.96, S D=2.28$ versus $M=7.42, S D=1.87$ on a 0 to 10 scale, $F(1,43,316)=94.33, p<$ $.001, R^{2}=.002, d=-0.24$; had fewer years of education, $M=$ $10.76, S D=2.08$ versus $M=11.32, S D=2.71, F(1,39,462)=$ $68.99, p<.001, R^{2}=.002, d=-0.21$; whereas no differences were found in gender representation. When compared with those SOEP participants who were also already deceased but did not provide data on perceived control, our current deceased subsample was, on average, younger at T1, $M=58.67$ years, $S D=13.96$ versus $M=66.19, S D=14.52, F(1,4,649)=317.71, p<.001$, $R^{2}=.064, d=-0.53$; whereas no differences were found for age at death, on levels of well-being at T1, gender, and education.

Respondents in our now-deceased sample participated in an average of $14.04(S D=5.64)$ assessments, with $94 \%$ contributing data on five or more occasions. On average, deaths occurred 14.89 years $(S D=5.69$; range: $1-25$ years) after participants' initial assessment and 1.85 years ( $S D=1.93$; range: $0-10$ years) after their last assessment. Participants contributed a total of 22,703 observations, and 1,419 persons $(\sim 86 \%)$ in the deceased sample provided data on well-being in the last three years of life.

\section{Measures}

Outcome. As a measure of well-being, we used responses to the question How satisfied are you with your life concurrently, all things considered? (in German: Wie zufrieden sind Sie gegenwärtig, alles in allem, mit ihrem Leben?), answered on a 0 (totally unsatisfied) to 10 (totally satisfied) scale. This item is considered a measure of cognitive-evaluative (as opposed to emotional) aspects of well-being and has been widely used in psychological research (e.g., Fujita \& Diener, 2005; Gerstorf, Ram, Estabrook et al., 2008; Lucas et al., 2003; Headey et al., 2010). We standardized responses from our deceased subsample to the larger, nationally representative SOEP sample. Specifically, responses were standardized to a $t$ metric $(M=50 ; S D=10)$ using the 2002 SOEP sample as the reference frame $(M=6.90, S D=1.81$ on a $0-10$ scale). Further details about measurement properties of the well- being measure as used in the SOEP can be obtained from Schimmack et al. (2008); Schilling (2006), and Fujita and Diener (2005).

Predictor. Perceived personal control was assessed using three items capturing whether or not participants' perceived their life to be under their control: I determine most of what happens to me in life, My life is determined by my own behavior, and Most plans I make are successful. These items bear close resemblance to established measures of personal mastery, as included in the Americans' Changing Lives Study (ACL; House et al., 1990) and the Midlife in the United States Survey (MIDUS; Lachman \& Weaver, 1998) such as the following: I can do just about anything I really set my mind to. Participants responded on a scale from 1 (completely disagree) to 4 (completely agree). Given that only three items were combined, the reliability of the scale was satisfactory (Cronbach's alpha $=.68$ ) and comparable to those reported in other studies (Lachman \& Weaver, 1998, used four items of personal mastery in the MIDUS: Cronbach's alpha $=.70$; Infurna, Gerstorf, \& Zarit, 2011 used six items from Pearlin \& Schooler's, 1978 Mastery Scale in the ACL: Cronbach's alpha = .66). Nevertheless, the moderate internal consistency provides impetus to independently replicate and extend the initial results reported from the current study. As can be obtained from Figure 1A, perceived control was assessed in this way in the years 1994, 1995, and 1996. For our analysis, we used, for each participant, the most recent report of perceived control: 1996 reports for 1,313 participants; 1995 for 173 participants; and 1994 for 165 participants. In follow-up analyses, we reran our models with an index that averaged across all available assessments of perceived personal control. Analyses revealed substantively the same pattern of results as reported in the text.

Because of the SOEP study design, perceived control was assessed, on average, in reasonably far distance to death $(M=6.12$ years; $S D=3.93$; range: $0-14$ ). In our view, perceived control as assessed here can be expected to be relatively unaffected by mortalityrelated processes (correlation with time-to-death $=-.08, p<.01$ ) and constitute resources that participants could draw from when being confronted with the challenges that typically accompany the
A

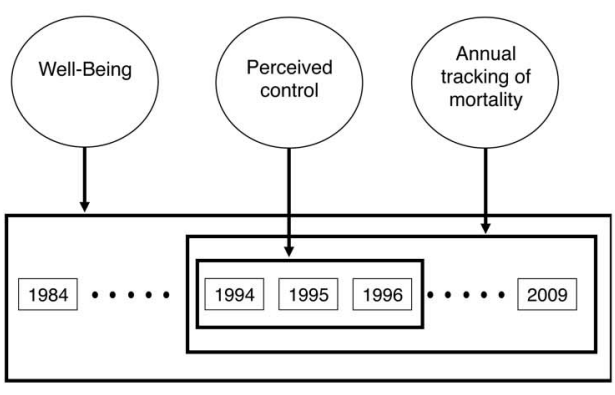

B

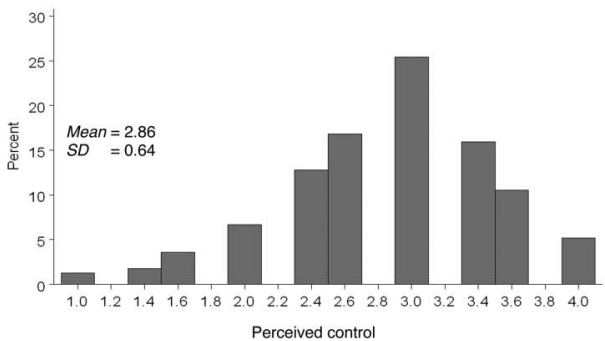

Figure 1. Overview of data collected in the German Socioeconomic Panel (SOEP) Study, as used in the present study. The SOEP data collection of well-being began in 1984 and continued through 2009, with a total of 26 annual waves. Perceived control was assessed three times between 1994 and 1996. Participants included in our study died between 1994 and 2009, as obtained by the yearly tracking of information about mortality status and time of death. In the current report, we used well-being and mortality information to estimate late-life trajectories of well-being and examined the moderating role of perceived personal control. 
last years of life. We also found empirical evidence that perceived control was relatively stable across the three years (e.g., change 1994 to 1996: $M=-0.019, S E=0.018)$. Nevertheless, we included an additional covariate into our analyses that indicated the length of the time interval that had elapsed in-between assessments of perceived control and participants' death. Of interest was whether the length of the interval had an effect on the strength of associations between perceived control and late-life levels of wellbeing and the rate of terminal decline, respectively. In the Discussion, we will consider how perceived control itself may change in close proximity to death. As shown in Figure 1B, our measure of perceived control roughly follows a normal distribution, and is somewhat biased toward the upper end of the scale. Finally, it may be worth noting that the three items on perceived control available in SOEP imply that the individual is actively and successfully striving to control his or her life, which not only reflects perceived control but also active striving for controlling one's life, a dispositional striving for primary control which according to the Motivational Theory of Life-Span Development is considered relatively time-invariant across the adult life span (see Figure 1 in Heckhausen et al., 2010).

Covariates. To control for known correlates of mortality, perceived control, and well-being, our models included five covariates: age at death, gender, education, and disability, and the time elapsed between assessment of perceived control and participant death. Given some nonlinearity in its relation with well-being (e.g., Gerstorf, Ram, Goebel et al., 2010), age-at-death was coded as a three-category grouping variable: Individuals who died before reaching age 70 years $(n=562)$, those who died when between 70 and 79 years $(n=456)$, and those who died after reaching age 80 years $(n=623)$. To preserve robustness of our models, we chose to include age at death only as opposed to additionally including age at baseline testing. In future studies, it may thus be informative to explore cohort effects in how perceived personal control operates. Using individuals' most recent reports, years of completed education were noted as the minimum number of years an individual needed to acquire his or her particular degree. Finally, disability was assessed at each wave with a single item asking participants whether they had been "officially certified as having a reduced capacity to work or being severely handicapped" (for details, see Lucas, 2007). Thus, disability indicators were based on self-reports, but referred to official certifications. Our measure contrasts all participants who had been disabled at some point during the study $(n=814)$ and those who were not $(n=827)$.

\section{Data Preparation and Data Analysis}

Participant's time-to-death was noted for each available assessment as the number of years remaining in that individuals' life. To illustrate the layout of the data, descriptive statistics for well-being over time-to-death are reported in Table 1 . It can be seen that average levels of well-being decline with closeness to death (e.g., $M=50.01$ at 12 years prior to death, $M=41.38$ in the year before death).

To examine our research questions, we estimated two sets of models. In a first set of models, we fitted single-phase growth curve models for well-being over time-to-death to effectively model between-person differences in how individuals' well-being
Table 1

Descriptive Statistics for Well-Being Over Time-to-Death

\begin{tabular}{lrcc}
\hline & \multicolumn{3}{c}{ Well-being over time-to-death } \\
\cline { 2 - 4 } Year & $n$ & $M$ & $S D$ \\
\hline-25 & 39 & 53.24 & 12.60 \\
-24 & 107 & 52.20 & 12.91 \\
-23 & 161 & 52.75 & 12.09 \\
-22 & 240 & 53.31 & 11.52 \\
-21 & 322 & 52.85 & 11.35 \\
-20 & 402 & 52.50 & 11.06 \\
-19 & 473 & 52.44 & 11.03 \\
-18 & 553 & 52.69 & 10.95 \\
-17 & 658 & 51.34 & 11.85 \\
-16 & 754 & 51.07 & 11.21 \\
-15 & 847 & 51.17 & 10.99 \\
-14 & 951 & 50.77 & 11.03 \\
-13 & 1,062 & 50.65 & 11.19 \\
-12 & 1,171 & 50.01 & 11.35 \\
-11 & 1,299 & 49.84 & 11.31 \\
-10 & 1,344 & 49.89 & 11.37 \\
-9 & 1,373 & 49.61 & 11.31 \\
-8 & 1,373 & 48.83 & 11.62 \\
-7 & 1,399 & 48.45 & 11.32 \\
-6 & 1,404 & 48.01 & 11.94 \\
-5 & 1,424 & 47.36 & 12.45 \\
-4 & 1,425 & 46.36 & 12.35 \\
-3 & 1,375 & 45.73 & 13.62 \\
-2 & 1,334 & 44.91 & 11.76 \\
-1 & 1,204 & 41.38 & 5.35 \\
0 & 9 & 42.57 & \\
\hline & & & \\
\hline
\end{tabular}

Note. $n=1,641$ participants who provided 22,703 observations. Scores were standardized to a $t$ metric $(M=50 ; S D=10)$ using the 2002 SOEP sample as the reference frame $(M=6.90, S D=1.81$ on a $0-10$ scale $)$.

changed with impending mortality. This model was specified as follows:

$$
\begin{aligned}
\text { well-being }_{t i}= & \beta_{0 i}+\beta_{1 i}(\text { time-to-death } \\
& \\
& +\beta_{2 i}\left(\text { time-to-death } h_{t i}^{2}\right)+e_{t i},
\end{aligned}
$$

where person $i$ 's well-being at time $t$, well-being ${ }_{t i}$, is a function of an individual-specific intercept parameter, $\beta_{0 i}$, individual-specific linear and quadratic slope parameters, $\beta_{1 i}$ and $\beta_{2 i}$, that capture the linear and quadratic rates of terminal decline per year over timeto-death and residual error, $e_{t i}$. Following standard multilevel/ latent growth modeling procedures (Ram \& Grimm, 2007; Singer $\&$ Willett, 2003), individual-specific intercepts, $\beta_{0 i}$, and slopes, $\beta_{1 i}$ and $\beta_{2 i}$, (from the Level 1 model given in Equation 1) were modeled as follows:

$$
\begin{aligned}
& \beta_{0 i}=\gamma_{00}+u_{0 i}, \\
& \beta_{1 i}=\gamma_{10}+u_{1 i}, \text { and } \\
& \beta_{2 i}=\gamma_{20}+u_{2 i},
\end{aligned}
$$

(i.e., Level 2 model) where $\gamma_{00}, \gamma_{10}$, and $\gamma_{20}$ are sample means, and $u_{0 i}, u_{1 i}$, and $u_{2 i}$ are individual deviations from those means that are assumed to be multivariate normally distributed, correlated with each other, and uncorrelated with the residual errors, $e_{t i}$. Cubic terms were also included and tested, but were not significantly different from zero and were thus not included in the final 
models. The time-to-death variable was centered at three years before death.

To examine whether and how the between-person variance in individuals' change trajectories over time-to-death was associated with perceived control and the covariates, additional predictors and covariates were added at the between-person level (Level 2). With the exception of age, where those deceased between ages 70 and 80 served as the reference group, and the time interval in-between perceived control assessments and death that was centered at five years, predictors were effectcoded/centered so that the regression parameters for these predictors indicated the average trajectory and the extent of differences associated with a particular variable (rather than for a particular group). Negative parameters indicate differences at the "disadvantage" of individuals reporting lower perceived control, surviving to an older age, women, those with lower SES, disabled participants, and the time interval that had elapsed in-between assessments of perceived control and participants' death. The expanded model took the following form:

$$
\begin{aligned}
& \beta_{0 i}=\gamma_{00}+\gamma_{01}\left(\text { died } \leq 69 \text { years }_{i}\right)+\gamma_{02}\left(\text { died } 80+\text { years }_{i}\right) \\
& +\gamma_{03}\left(\text { gender }_{i}\right)+\gamma_{04}\left(\operatorname{SES}_{i}\right)+\gamma_{05}\left(\text { disability }_{i}\right) \\
& +\gamma_{06}\left(\text { perceived } \operatorname{control}_{i}\right) \\
& +\gamma_{07}\left(\text { time perceived control assessment }- \text { death }_{i}\right)
\end{aligned}
$$

$+\gamma_{08}$ (perceived control $_{i} \times$ time $_{\text {perceived control assessment }}$

$$
\left.- \text { death }_{i}\right)+u_{0 i}
$$

and

$$
\begin{aligned}
& \beta_{1 i}=\gamma_{10}+\gamma_{11}\left(\text { died } \leq 69 \text { years }_{i}\right)+\gamma_{12}\left(\text { died } 80+\text { years }_{i}\right) \\
& +\gamma_{13}\left(\text { gender }_{i}\right)+\gamma_{14}\left(\operatorname{SES}_{i}\right)+\gamma_{15}\left(\text { disability }_{i}\right) \\
& +\gamma_{16}\left(\text { perceived } \text { control }_{i}\right) \\
& +\gamma_{17}\left(\text { time perceived control assessment }- \text { death }_{i}\right)
\end{aligned}
$$

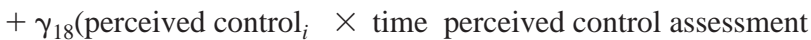

$$
\left.- \text { death }_{i}\right)+u_{1 i}
$$

We also included main effects of perceived control and each covariate on the curvature of the average change trajectories (i.e., quadratic change) and tested for interaction effects with perceived control; only those effects that reliably differed from zero were retained in the final models.

In a second set of models, we invoked notions of terminal decline by using extensions (Cudeck \& Harring, 2007; Cudeck \& Klebe, 2002) of multiphase or "spline" growth models (Ram \& Grimm, 2007; Singer \& Willett, 2003). Specifically, models were specified as

$$
\begin{aligned}
& \text { well-being }_{t i}=\beta_{0 i}+\beta_{1 i}\left(\text { time-to-death }_{t i}-k\right)+e_{t i}, \\
& \text { when } D t D_{t i}<k, \text { and } \\
& \text { well-being }{ }_{t i}=\beta_{0 i}+\beta_{2 i}\left(\text { time-to-death }_{t i}-k\right)+e_{t i}, \\
& \text { when } D t D_{t i} \geq k,
\end{aligned}
$$

where individual-specific rates of change in the preterminal phase are captured by $\beta_{1 i}$, and individual-specific rates of change after the transition point (i.e., terminal-phase) are captured by $\beta_{2 i}$. The point of transition from one phase to the other, $k$, is a free (fixed effect) parameter estimated from the data, with $\beta_{0 i}$ capturing individuals' estimated level of well-being at this transition point.

To examine whether and how perceived control and the covariates predicted the location of the transition point, the model was expanded at level-2 as follows:

$$
\begin{aligned}
& \beta_{0 i}=\gamma_{00}+u_{0 i} \\
& \beta_{1 i}=\gamma_{10}+u_{1 i} \\
& \beta_{2 i}=\gamma_{20}+u_{2 i} \\
& k_{i}=\alpha_{01}\left(\text { died } \leq 69 \text { years }_{i}\right)+\alpha_{02}\left(\text { died }_{80}+\text { years }_{i}\right)+\alpha_{03}\left(\text { gender }_{i}\right) \\
& +\alpha_{04}\left(\mathrm{SES}_{i}\right)+\alpha_{05}\left(\text { disability }_{i}\right)+\alpha_{06}\left(\text { perceived }_{\text {control }}\right) \\
& +\alpha_{07} \text { (time perceived control assessment }- \text { death }_{i} \text { ) } \\
& \left.+\alpha_{08} \text { (perceived control } \times \text { time perceived control assessment }- \text { death }_{i}\right) \\
& +u_{3 i}
\end{aligned}
$$

We note that despite relatively extensive longitudinal observations, it was not possible to estimate models that simultaneously estimated individual differences in all three aspects of late-life trajectories we are interested in (level, rates of terminal decline, onset of decline). Thus, random effects for between-person differences in the timing of the transition between preterminal and terminal phases were not included.

Models were fit to the data using SAS Proc Mixed (single-phase models) or Proc NLMixed (multiphase models; see Littell et al., 1996), with incomplete data accommodated under missing at random assumptions at the within-person level, and, to retain longitudinal data, missing completely at random at the between-person level (Little \& Rubin, 1987). The covariates included in our models (e.g., age, health) represent attrition-informative variables and so helped to accommodate longitudinal selectivity for the outcome variable of well-being (i.e., missingness may have been related to these variables; McArdle, 1994).

\section{Results}

In a preliminary step, we estimated an unconditional means model of well-being to examine the distribution of between-person and within-person variation. These analyses revealed that the intraclass correlation was .45 , suggesting that $45 \%$ of the total variation in well-being was between-person variation. Thus, at both levels of analyses - within individuals and between individuals-substantial variation in well-being was observed. We thus proceeded to describe and evaluate how this within-person and between-person variation was structured.

\section{Does Perceived Control Relate to Higher Late-Life Wellbeing and Less Severe Rates of Decline?}

In a first set of analyses, we used single-phase growth curve models for well-being over time-to-death to model between-person differences in how individuals' well-being changed with impending mortality and to explore the role of perceived control and the covariates. Results are reported in Table 2. Consistent with earlier work, we found that the typical trajectory of late-life well-being is characterized by linear decline with some acceleration. Specifi- 
Table 2

Single-Phase Model for Well-Being Over Time-to-Death, Including Perceived Control and the Covariates as Predictors of Differences in Levels and Rates of Linear and Quadratic Change

\begin{tabular}{|c|c|c|}
\hline \multirow[b]{2}{*}{ Parameter } & \multicolumn{2}{|c|}{ Well-being } \\
\hline & Estimate & $S E$ \\
\hline \multicolumn{3}{|l|}{ Fixed effects } \\
\hline Intercept, ${ }^{\mathrm{a}} \gamma_{00}$ & $46.97^{*}$ & $(0.555)$ \\
\hline Linear slope, ${ }^{\mathrm{a}} \gamma_{10}$ & $-0.66^{*}$ & $(0.076)$ \\
\hline Quadratic slope, $\gamma_{20}$ & $-0.02^{*}$ & $(0.004)$ \\
\hline Died $\leq 69$ years, $\gamma_{01}$ & $-1.82^{*}$ & $(0.584)$ \\
\hline Died $70-79$ years & - & - \\
\hline Died $80+$ years, $\gamma_{02}$ & 0.28 & $(0.569)$ \\
\hline Men, $\gamma_{03}$ & 0.75 & $(0.479)$ \\
\hline Education, $\gamma_{04}$ & 0.18 & $(0.112)$ \\
\hline Disability, $\gamma_{05}$ & $-3.76^{*}$ & $(0.472)$ \\
\hline Perceived control, $\gamma_{06}$ & $4.13^{*}$ & $(0.522)$ \\
\hline Time perceived control-death, $\gamma_{07}$ & $-0.36^{*}$ & $(0.590)$ \\
\hline Perceived control $\times$ Time perceived control-death, $\gamma_{08}$ & 0.07 & $(0.091)$ \\
\hline Linear slope $\times$ Died $\leq 69$ years, $\gamma_{11}$ & 0.03 & $(0.052)$ \\
\hline Linear slope $\times$ Died $70-79$ years & - & - \\
\hline Linear slope $\times$ Died $80+$ years, $\gamma_{12}$ & $-0.14^{*}$ & $(0.049)$ \\
\hline Linear slope $\times$ Men, $\gamma_{13}$ & 0.04 & $(0.042)$ \\
\hline Linear slope $\times$ Education, $\gamma_{14}$ & $0.02^{*}$ & $(0.010)$ \\
\hline Linear slope $\times$ Disability, $\gamma_{15}$ & $-0.30^{*}$ & $(0.088)$ \\
\hline Linear slope $\times$ Perceived control, $\gamma_{16}$ & $0.12^{*}$ & $(0.034)$ \\
\hline Linear slope $\times$ Time perceived control-death, $\gamma_{17}$ & $-0.01^{*}$ & $(0.006)$ \\
\hline Linear slope $\times$ Perceived control $\times$ Time perceived control-death, $\gamma_{18}$ & -0.02 & $(0.009)$ \\
\hline Quadratic slope $\times$ Disability, $\gamma_{19}$ & $-0.01^{*}$ & $(0.005)$ \\
\hline Disability $\times$ Perceived control, $\gamma_{110}$ & $1.85^{*}$ & $(0.605)$ \\
\hline \multicolumn{3}{|l|}{ Random effects } \\
\hline Variance intercept & $70.26^{*}$ & $(3.023)$ \\
\hline Variance linear slope & $1.57^{*}$ & $(0.110)$ \\
\hline Variance quadratic slope & $0.004^{*}$ & $(0.000)$ \\
\hline Covariance intercept, linear slope & $3.92^{*}$ & $(0.438)$ \\
\hline Covariance intercept, quadratic slope & $0.07^{*}$ & $(0.025)$ \\
\hline Covariance linear slope, quadratic slope & $0.07^{*}$ & $(0.006)$ \\
\hline Residual, $\sigma_{e}^{2}$ & $62.32^{*}$ & $(0.649)$ \\
\hline Pseudo $R^{2}$ & \multirow{2}{*}{\multicolumn{2}{|c|}{$\begin{array}{c}.232 \\
164,522\end{array}$}} \\
\hline$A I C$ & & \\
\hline
\end{tabular}

Note. Unstandardized estimates and standard errors are presented. Time perceived control $=$ time interval that had elapsed in-between assessments of perceived control and participants' death. $n=1,641$ participants who provided 22,703 observations. Scores were standardized to a $t$ metric $(M=50 ; S D=10)$ using the $2002 \mathrm{SOEP}$ sample as the reference frame $(M=6.90, S D=1.81$ on a $0-10$ scale). Participants who died between 70 and 79 years of age served as the reference group. Two-way and three-way interaction terms of the quadratic slope and of perceived control were tested, but only those reliably different from zero were retained in the final model. $A I C=$ Akaike Information Criterion, a relative model fit statistic.

${ }^{\mathrm{a}}$ Intercept is centered at three years before death. ${ }^{\mathrm{b}}$ Slope or rate of change is scaled in $t$ units per year.

${ }^{*} p<.05$.

cally, the linear component of decline amounted to some two thirds of a standard deviation per 10 years $\left(\gamma_{10}=-0.66\right)$, which together with some concave curvature $\left(\gamma_{20}=-0.02\right)$ brought the average individual to a well-being level at three years prior to death $\left(\gamma_{00}=\right.$ 46.97) that was a little less than half a standard deviation below the mean of the nationally representative SOEP sample in $2002(M=$ $50, S D=10$ ).

We also found that the covariates were associated with levels and terminal decline in well-being. To begin with, relative to those who died in their $70 \mathrm{~s}$, participants who died before age 70 reported lower well-being close to death $\left(\gamma_{01}=-1.82\right)$ and participants who died after age 80 reported steeper late-life declines in wellbeing $\left(\gamma_{13}=-0.14\right)$. Interestingly, more educated persons also reported slightly steeper late-life declines $\left(\gamma_{14}=-0.02\right)$. Results also revealed that participants with disability reported lower levels of well-being $\left(\gamma_{05}=-3.76\right)$ and experienced both more precipitous linear declines $\left(\gamma_{15}=-0.30\right)$ and quadratic rates of decline $\left(\gamma_{19}=-0.01\right)$. No significant differences were found for gender.

Most important for our research question, results revealed that perceived personal control was a moderator of late-life well-being: Participants who perceived more control reported higher wellbeing three years prior to death $\left(\gamma_{06}=4.13\right)$ and experience less severe end-of-life declines in well-being $\left(\gamma_{16}=0.12\right)$. Of note is that this pattern of results was not dependent upon the time interval that had elapsed in-between assessments of perceived control and participants' death: There were main effects of the time interval (level: $\gamma_{07}=-0.36$; slope: $\gamma_{17}=-0.01$ ), suggesting that participants whose perceived control had been assessed further away from death reported slightly lower well-being and slightly steeper decline. However, its associations with the effects of perceived 
control on level $\left(\gamma_{08}=0.07, S E=0.09, \mathrm{~ns}\right)$ and on rate of terminal decline $\left(\gamma_{18}=-0.02, S E=0.009\right.$, ns $)$ were each not reliably different from zero.

To illustrate our major effect of interest, Figure 2 contrasts trajectories of terminal decline in well-being between participants high and low on perceived control. Using a median-split for this illustration, one can see that participants who report more perceived control also report higher late-life well-being and experience fewer declines. Finally, Table 2 also reports an interaction between perceived control and disability $\left(\gamma_{110}=1.85\right)$, suggesting that the lower well-being reports when disability was present were alleviated for individuals with higher levels of perceived control. The predictors included in the model accounted for a total of $23 \%$ of the variance in late-life trajectories of well-being, with the following BICs (Bayesian Information Criterion) of models that did or did not include the perceived control variables: 164,673 versus 164,859 .

\section{Does Perceived Control Relate to a Later Onset of Terminal Decline in Well-Being?}

In a second set of analysis, we used two-phase models of change to identify the typical location of the change point to terminal well-being decline and to examine whether perceived control predict a later onset of such terminal declines over and above the effects of the covariates. Results are reported in Table 3. It can be obtained that the typical individual transitioned into the terminal phase of well-being decline at 4.99 years, after which the rate of decline steepened by a factor of 4.9 from $0.24 t$ score units per year to $1.17 t$ score units per year. Several of the covariates included were found to predict individual differences in the onset of terminal well-being decline. Specifically, participants who died after age $80\left(k_{1}=-0.59\right)$, women $\left(k_{3}=0.77\right)$, less educated partici-

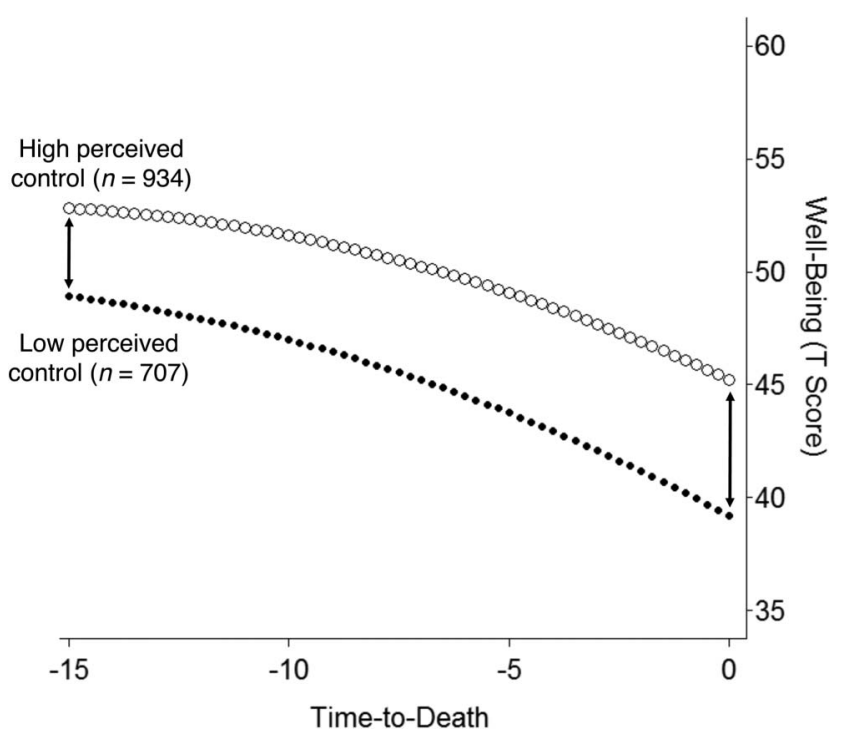

Figure 2. Graphic illustration of the effects of perceived control on late-life trajectories of well-being, as obtained from single-phase models. Participants who reported perceiving more personal control over one's life also reported higher late-life well-being and experienced fewer declines. pants $\left(k_{4}=0.27\right)$, and those suffering from disability $\left(k_{5}=-2.41\right)$ each spent more time in the terminal phase of decline.

Most important for the test of our hypothesis, we again found evidence that perceived personal control was a moderator of latelife well-being: Participants who reported higher perceived control entered the phase of precipitous well-being decline later $\left(k_{6}=\right.$ 1.98). The effect size of almost two years per one unit of perceived control, which is residualized for the predictive effects of the other covariates, is striking. To illustrate, Figure 3 contrasts terminal decline trajectories for well-being between participants high and low on perceived control. Using a median-split for this illustration, one can see that participants who reported more perceived control enter the phase of precipitous well-being decline later. The predictors included in the multiphase model accounted for a total of $24 \%$ of the variance in late-life trajectories of well-being, with the following BICs (Bayesian Information Criterion) of models that did or did not include the perceived control variables: 164,722 versus 164,797 .

Of note is also that the predictive effect of perceived control was only minimally shaped by the time interval that had elapsed in-between assessments of perceived control and participants' death: There was a main effect of the time interval $\left(k_{7}=-0.25\right)$, suggesting that participants whose perceived control had been assessed further away from death spent more time in terminal decline. The interaction term $\left(k_{8}=-0.13\right)$ suggests that the predictive effect of perceived control for the location of the change point was getting smaller the further away from death people's perceived control had been assessed.

\section{Discussion}

Our major objective was to examine the role of perceived personal control for terminal decline in well-being. Our hypothesis was that perceived control contributes to the adaptive systems that promote individual functioning and well-being and may help to ameliorate or delay the onset of a terminal decline in well-being. First, in single-phase models, analyses revealed that self-reports of perceived control were indeed related to both subsequent higher late-life well-being and less severe rates of late-life declines. Second, multiphase models of change indicated that participants who reported higher perceived control entered the phase of precipitous decline in well-being later. Both findings were independent of age, gender, SES, and disability - all of which are known predictors of mortality, perceived control, and well-being. We take our results to suggest that perceiving control over one's life protects against end-of-life terminal decline in well-being. In our discussion, we consider the implications of these findings and also explore the potential limits of perceived control-based benefits in terms of specific scenarios for when and how processes of goal disengagement and giving up control may become beneficial.

\section{Perceived Control and Terminal Decline in Well-Being}

Closely in line with earlier studies that have used more comprehensive assessments of well-being (Berg et al., 2011; Diehr et al., 2002; Gerstorf, Ram, Mayraz et al., 2010; Palgi et al., 2010; Schilling et al., 2012; Vogel et al., 2012), our report based on a single well-being item indicates that well-being shows precipitous decline late in life that typically set-in within a three-to-five year 
Table 3

Multi-Phase Model for Well-Being Over Time-to-Death, Including Perceived Control and the Covariates as Predictors of Differences in the Location of the Inflection Point

\begin{tabular}{lcc}
\multicolumn{1}{c}{ Parameter } & Estimate & $S E$ \\
\hline Fixed effects & & \\
Intercept, ${ }^{\mathrm{a}} a_{00}$ & $48.85^{*}$ & $(0.255)$ \\
Inflection point, $k$ & $-4.99^{*}$ & $(0.257)$ \\
Pre-terminal slope, ${ }^{\mathrm{b}} a_{01}$ & $-0.24^{*}$ & $(0.027)$ \\
Terminal slope, ${ }^{*} a_{02}$ & $-1.17^{*}$ & $(0.064)$ \\
Died $\leq 69$ years $\times$ Change point, $k$ & 0.10 & $(0.264)$ \\
Died 70-79 years $\times$ Change point, $k$ & - & - \\
Died 80+ years $\times$ Change point, $k$ & $-0.59^{*}$ & $(0.247)$ \\
Men $\times$ Change point, $k$ & $0.77^{*}$ & $(0.213)$ \\
Education $\times$ Change point, $k$ & $0.27^{*}$ & $(0.057)$ \\
Disability $\times$ Change point, $k$ & $-2.41^{*}$ & $(0.214)$ \\
Perceived control $\times$ Change point, $k$ & $1.98^{*}$ & $(0.197)$ \\
Time perceived control-death $\times$ Change point, $k$ & $-0.25^{*}$ & $(0.029)$ \\
Perceived control $\times$ Time perceived control-death $\times$ Change point, $k$ & $-0.13^{*}$ & $(0.048)$ \\
Random effects & & \\
Variance intercept & $78.73^{*}$ & $(3.423)$ \\
Variance pre-terminal slope & $0.47^{*}$ & $(0.039)$ \\
Variance terminal slope & $2.45^{*}$ & $(0.224)$ \\
Covariance intercept, pre-terminal slope & $3.04^{*}$ & $(0.292)$ \\
Covariance intercept, terminal slope & $-5.29^{*}$ & $(0.632)$ \\
Covariance pre-terminal slope, pre-terminal slope & $-0.19^{*}$ & $(0.066)$ \\
Residual variance & $61.71^{*}$ & $(0.65)$ \\
Pseudo $R^{2}$ & & .239 \\
AIC & & 164,619 \\
\hline
\end{tabular}

Note. Unstandardized estimates and standard errors are presented. $n=1,641$ participants who provided 22,703 observations. Scores were standardized to a $t$ metric $(M=50 ; S D=10)$ using the 2002 SOEP sample as the reference frame $(M=6.90, S D=1.81$ on a $0-10$ scale). Participants who died between 70 and 79 years of age served as the reference group. Two-way and three-way interaction terms of the quadratic slope and of perceived control were tested, but only those reliably different from zero were retained in the final model. AIC = Akaike Information Criterion, a relative model fit statistic.

${ }^{\mathrm{a}}$ Intercept is centered at the change point. ${ }^{\mathrm{b}}$ Slope or rate of change is scaled in $t$ units per year.

$* p<.05$.

window before death. Consistent with earlier reports (Gerstorf, Ram et al., 2013), we found that surviving to an older age, being a woman, lower socioeconomic status and presence of pathological aging (e.g., disability) are associated with less favorable terminal decline trajectories. Our findings are in line with earlier studies that very old people may not have the adaptive capabilities anymore to ward off the pervasive nature of mortality-related processes (Baltes \& Smith, 2003). Probably most striking among our findings regarding general (e.g., demographic, health-status related) individual differences was that participants suffering from some form of disability reported lower levels of well-being, experienced more precipitous linear and quadratic rates of decline, and also spent more time in the terminal phase of decline.

The main purpose of our study, though, was to investigate the role of psychological characteristics for the prediction of the trajectory of end-of-life well-being. Our findings are (among) the first to provide evidence that particular psychological characteristics indeed serve as moderators of late-life decline and can up- or downregulate well-being trajectories. In fact, some of the effect sizes were quite impressive. To begin with, the unique association between a one-unit difference in perceived control (on a Likert scale from 1 to 4) and late-life well-being was as strong as, if not stronger than, the association of being disabled (relative to not being disabled) and late-life well-being (see Table 2: $\gamma_{06}=4.13$ and $\gamma_{05}=-3.76$ ). In a similar vein, being one unit higher on perceived control (on a Likert scale from 1 to 4 , though this admittedly corresponds to a $1.5 S D$ difference, see Figure $1 \mathrm{~B}$ ) was associated with spending almost two years less in the terminal phase of decline, independent of the effects of age at death, gender, education, and disability.

The present study is the first to document that psychological characteristics indeed substantially contribute to individual differences in late-life well-being. These findings highlight the critical role of our self-regulation system for how people experience their last years of life. They demonstrate that control perceptions remain important resources to deal with and adjust to the challenges of late life. There are several ways in which perceived control may contribute to protecting subjective well-being at the end of life.

First, people who consider themselves to be in control of and actively engaged with shaping their lives often have adaptive strategies to begin with. To illustrate, perceived control is frequently regarded as a general-purpose mechanism that helps in the fulfillment of personal needs and a resource that people can draw upon in the face of obstacles (Baltes, 1997; Heckhausen \& Schulz, 1995, 1999; Lawton, 1990). For example, individuals perceiving themselves as being in control may know of, have access to, and be able to mobilize emotional and instrumental support from others, particularly in times of strain, and thereby compensate for scarce and declining individual resources (see Antonucci, 2001; Heckhausen \& Schulz, 1995; Lang et al., 1997; Pearlin \& 


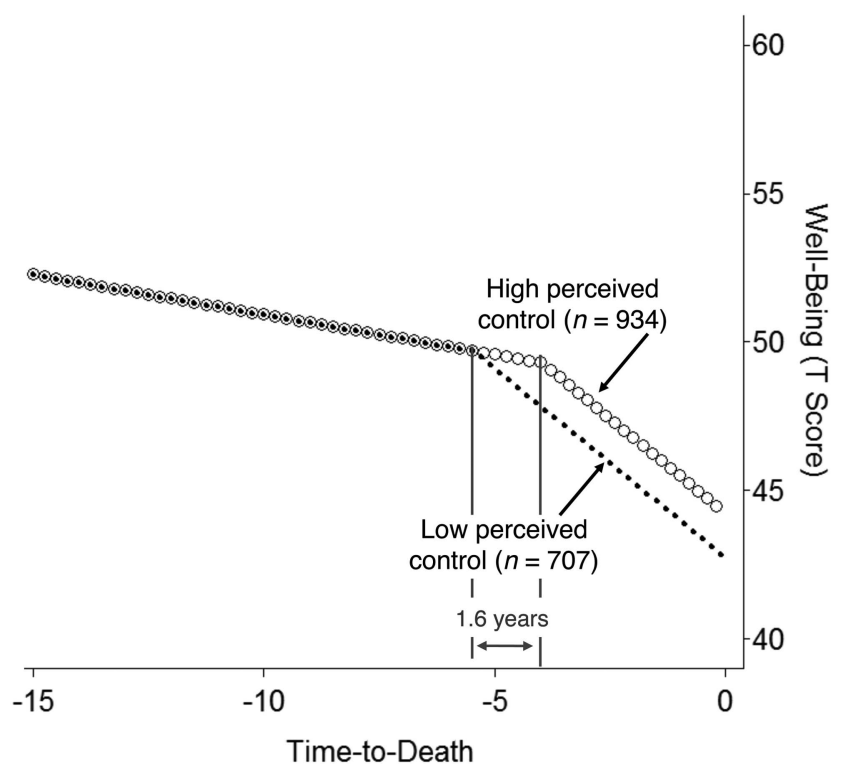

Figure 3. Graphic illustration of the effects of perceived control on late-life trajectories of well-being, as obtained from multiphase models. Participants who reported perceiving more personal control over one's life entered the phase of precipitous well-being decline later.

Schooler, 1978; Skaff, 2007; Uchino, 2006). Consistent with this line of reasoning, our results show that well-being for these highcontrol people often starts declining from a higher level and/or is less at risk of decline.

Second, a sense of control may also help people to use and exploit their remaining capabilities, thus ameliorating functional deterioration and as a consequence postpone a terminal drop in well-being (Heckhausen, Wrosch, \& Schulz, 2013). Perceived control has been found to predict engagement and persistence in goal-related activities, particularly in the face of difficulties and to help people focus on goals that are attainable and domains that can still be influenced despite overall declining resources (Heckhausen et al., 2010). Corroborating these associations, our results revealed that higher levels of perceived control in the presence of disability alleviated lower well-being reports. This finding is consistent with conceptual approaches to disability such as the Disablement Process Model (Verbrugge \& Jette, 1994) that highlight the moderating role of personal resources in the context of disability progression. For example, people who perceive themselves to be in control may make better use of remaining resources such that functional limitations do not necessarily turn into full-blown disability and thereby alleviate disability-related well-being decrements.

Third, to protect their motivational-emotional resources, older adults in advanced old age can be expected to be willing to disengage from goals that have become extremely difficult or costly to attain. The Motivational Theory of Life-Span Development proposes that individuals adjust their goals to available control opportunities and thus achieve an adaptive congruence with beneficial consequences for developmental outcomes, health, longevity and well-being (Heckhausen et al., 2010). At the very end of life, goal disengagement may become increasingly relevant because it allows people to let go of futile goals and those areas of functioning which cannot be influenced any more (Heckhausen et al., 2013). The more challenging the life conditions, the more important and more functional it should be to adjust one's perceptions of and striving for control to the shrinking of available resources. In line with this argument, empirical evidence suggests that with increased functional limitations people surrender aspects of self-reliance that are less meaningful for themselves in order to retain autonomy in goal domains that they cherish (M. M. Baltes, 1996; Johnson \& Barer, 1997). For example, older adults may be less inclined to draw on domains such as health and physical fitness as sources of control because of the increased risks for major health losses and the slim chance for improvements (Rodin, 1986). Instead, people in advanced old age may increasingly attempt to derive their sense of control from more attainable goals, such as endeavors associated with one's social relationships (Heckhausen et al., 2010). In a similar vein, perceptions of control can help people adjust priority structures. For example, processes of self-protective cognitive restructuring may be particularly effective, according to which people come to terms with unattainable goals by adjusting their aspiration levels, devaluing initially important goals, and redirecting their attention to downward social comparisons (see Heckhausen \& Schulz, 1995). Disentangling these specific strategies was not possible with the data currently available. The nature of the items available for our archival data analysis predominantly allowed testing hypotheses about one component of perceptions of control, but lent itself less to examine other components of the larger construct space, including goal engagement and disengagement and the congruence of control striving with control opportunities. Currently ongoing empirical work will result in the appropriate longitudinal assessment of control strategies in due course (Heckhausen \& Gerstorf, 2011).

\section{Limitations and Outlook}

We note several limitations of our study. To begin with, one central limitation of our study is that the psychometric properties of single-item measures (like our well-being outcome) are lower than those of comprehensive multiitem or multiscale measures. For example, single-item measures are not very sensitive to pick-up subtle changes in the underlying phenomenon and can thus be expected to constrain the range of variability observed. We also acknowledge that more comprehensive well-being measures or those which tap into different well-being aspects (e.g., affect) may reveal different associations to those reported here. Moreover, because feeling in control has been shown to buffer negative emotions (Kunz-Ebrecht et al., 2004; Neupert et al., 2007), it is also possible that the buffering effect of perceived personal control is probably more pronounced for measures that tap into affective components of well-being rather than those that tap into more cognitive-evaluative components.

One limitation of our key predictor variable was that we identified those participants who are confident that their endeavors for control will be successful without separating perceptions of control (i.e., a social cognition) and strivings for control (i.e., a motivation). As a domain-generalized index of primary control, the measure also did not help us distinguish between perceived control over different domains of life, how it is shaped by social support, and it was also not possible to disentangle perceived control from the expectations people have about exercising control and from 
how much control they desire to have about their life. It is also unfortunate that indices of secondary control strategies are not yet available in the SOEP up to now. Such measures will be highly informative about the dynamic interplay between primary strategies of goal engagement when control can indeed be exercised, volitional investment when control is under threat, and secondary strategies of goal disengagement when control cannot be exercised anymore, and the subsequent reengagement with new and more feasible goals (i.e., opportunity congruence). Aspects of primary control may become less important when people are very close to death because they then may lack the resources and capacities to realize their control aspirations; instead, the remaining control endeavors often focus on less ambitious health goals and people reorient toward psychological, generative, and spiritual goals (see lines of defense model: Heckhausen et al., 2013). With domaintailored measures of the perceptions of and strivings for control just being added to the assessment protocol of the SOEP (Heckhausen \& Gerstorf, 2011), we can address such ideas in some years (when the number of events has become large enough) and move beyond our primarily descriptive approach. We expect then to thoroughly address specific control-related processes, for example when frail older adults focus on their most cherished activities and people at the expense of less valued ones. It will also be highly intriguing in future research to pursue more integrated routes of inquiry and explore the shared, unique, and particularly the interactive moderating effects of perceived personal control with personality trait variables (see Chapman, Fiscella, Kawachi, \& Duberstein, 2010; Mroczek, Spiro, \& Griffin, 2006; Winter, John et al., 1998) once these become more and more available in the SOEP. For example, we would expect that a combination of high neuroticism and a lack of perceived control over one's life constitutes a risk factor for well-being decline that reveals predictive effects over and above those of neuroticism and perceived control alone.

As a limitation of the data collection design, we note that control assessments were obtained several years before people died (on average, six years). As a consequence, the measure provided an index of the resources people bring into late life, whereas we do not have information about how preserved this resource is very late in life. Initial evidence reporting that control is embedded in the evolving system of late-life decline and also shows precipitous decrements (Gerstorf, Ram et al., 2013) suggest that this resource may indeed be compromised late in life. Interestingly, in our study there was no indication whatsoever that the effects of perceived control on between-person differences were getting smaller with impending death. Quite to the contrary, if anything, results (see $k_{8}$ in Table 3) suggest that the further away from death perceived control was assessed, the smaller the effects were. However, to thoroughly track how mortality-related decrements in control beliefs change its predictive utility for late-life well-being, we would need extensive data on within-person change rather than those on between-person differences as used herein. We also note that different dynamics may emerge than the ones reported here when research zooms into people's everyday life. For example, it would be highly informative to track when and how the daily life dynamics late in life are indeed in line with the goals people have and with the (perceived and objective) control potential people can exercise over a given situation. We also had no information about cause of death available although it would have been instrumental to examine whether or not the moderating effects of perceived control differed between the conditions of the dying process. Combined with the domain-tailored measures currently being added to the SOEP, we would expect that disengaging from health goals would be particularly beneficial for people suffering from chronic diseases (e.g., respiratory conditions and cancer), primarily because there are increasingly fewer opportunities for successfully exercising control (see Hall et al., 2010; Heckhausen et al., 2013).

We also note several limitations of the models and data examined. For example, it was not possible to include random effects for the $k$ parameter (i.e., the location of the change point) so as to directly examine individual differences in the onset of terminal decline and to estimate models that simultaneously included individual differences in all three aspects of late-life trajectories we are interested in (level, rates of terminal decline, onset of decline). One major limiting factor was certainly that we have very little information about the last year of life, as illustrated by the fact that only nine observations were obtained in the last 12 months (see Table 1). It would also be intriguing to move from our current retrospective perspective toward more prospective analyses of the predictive effects of perceived control. For example, comparing wellbeing trajectories of change between survivors and decedents in a given study could be used to explore how perceived control might be more salient in mitigating well-being declines among nonsurvivors. Finally, it remains to be seen whether and how our results, obtained from deceased German respondents, generalize to other populations or geographic locations. For example, it would be highly informative to examine the role of perceived personal control in more collectivistic (sub)-cultures who value personal control and the perception (illusion) of it less highly.

\section{Conclusions}

Taken together, our results suggest that individual differences in perceived control moderate between-person differences in trajectories of terminal decline. We have little understanding yet about which particular aspects are involved, but the motivational theory of life span development (Heckhausen et al., 2010) helps to formulate specific hypotheses that can be tested in future research. Eventually, insights into why some people report higher wellbeing late in life, experience shallower rates of decline, or spend less time in the terminal phase may point to particular pathways for intervention (Baltes \& Baltes, 1990; Rowe \& Kahn, 1997) and thereby help individuals in this most difficult time of their life.

\section{References}

Antonucci, T. C. (2001). Social relations: An examination of social networks, social support, and sense of control. In J. E. Birren \& K. W. Schaie (Eds.), Handbook of the psychology of aging (pp. 427-453). San Diego, CA: Academic Press.

Baltes, M. M. (1996). The many faces of dependency in old age. New York, NY: Cambridge University Press.

Baltes, P. B. (1997). On the incomplete architecture of human ontogeny: Selection, optimization, and compensation as foundation of developmental theory. American Psychologist, 52, 366-380. doi:10.1037/0003066X.52.4.366

Baltes, P. B., \& Baltes, M. M. (Eds.). (1990). Successful aging: Perspectives from the behavioral sciences. New York, NY: Cambridge University Press. doi:10.1017/CBO9780511665684 
Baltes, P. B., \& Nesselroade, J. R. (1979). History and rationale of longitudinal research. In J. R. Nesselroade \& P. B. Baltes (Eds.), Longitudinal research in the study of behavior and development (pp. 1-39). New York, NY: Academic Press.

Baltes, P. B., \& Smith, J. (2003). New frontiers in the future of aging: From successful aging of the young old to the dilemmas of the fourth age. Gerontology, 49, 123-135. doi:10.1159/000067946

Berg, A. I., Hassing, L. B., Thorvadsson, V., \& Johansson, B. (2011). Personality and personal control make a difference for life satisfaction in the oldest-old: Findings in a longitudinal population-based study of individuals 80 and older. European Journal of Ageing, 8, 13-20. doi: 10.1007/s10433-011-0181-9

Birren, J. E., \& Cunningham, W. (1985). Research on the psychology of aging: Principles, concepts, and theory. In J. E. Birren \& K. W. Schaie (Eds.), Handbook of the psychology of aging (2nd ed., pp. 3-34). New York, NY: Van Nostrand Reinhold.

Brandstädter, J. (1999). Sources of resilience in the aging self: Toward integrating perspectives. In T. M. Hess \& F. Blanchard-Fields (Eds.), Social cognition and aging (pp. 123-141). San Diego, CA: Academic Press. doi:10.1016/B978-012345260-3/50007-0

Brandtstädter, J., \& Greve, W. (1994). The aging self: Stabilizing and protective processes. Developmental Review, 14, 52-80. doi:10.1006/ drev.1994.1003

Brickman, P., \& Campbell, D. T. (1971). Hedonic relativism and planning the good society. In M. Appley (Ed.), Adaptation-level theory (pp. 287-305). New York, NY: Academic Press.

Brockmann, H., \& Klein, T. (2004). Love and death in Germany: The marital biography and its effect on mortality. Journal of Marriage and Family, 66, 567-581. doi:10.1111/j.0022-2445.2004.00038.x

Burkhauser, R. V., Giles, P., Lillard, D. R., \& Schwarze, J. (2005). Until death do us part: An analysis of the economic well-being of widows in four countries. Journals of Gerontology Series B: Social Sciences, 60, S238-S246. doi:10.1093/geronb/60.5.S238

Caplan, L. J., \& Schooler, C. (2003). The roles of fatalism, self-confidence, and intellectual resources in the disablement process in older adults. Psychology and Aging, 18, 551-561. doi:10.1037/0882-7974.18.3.551

Carstensen, L. L. (2006). The influence of a sense of time on human development. Science, 312, 1913-1915. doi:10.1126/science.1127488

Chapman, B. P., Fiscella, K., Kawachi, I., \& Duberstein, P. R. (2010). Personality, socioeconomic status, and all-cause mortality in the United States. American Journal of Epidemiology, 171, 83-92. doi:10.1093/aje/ kwp323

Charles, S. T., Reynolds, C. A., \& Gatz, M. (2001). Age-related differences and change in positive and negative affect over 23 years. Journal of Personality and Social Psychology, 80, 136-151. doi:10.1037/00223514.80.1.136

Cohen, H. J. (2000). In search of the underlying mechanisms of frailty. Journal of Gerontology: Medical Sciences, 55, M706-M708. doi: 10.1093/gerona/55.12.M706

Cohen, S., \& Wills, T. A. (1985). Stress, social support, and the buffering hypothesis. Psychological Bulletin, 98, 310-357. doi:10.1037/00332909.98.2.310

Costa, P. T., Zonderman, A. B., McCrae, R. R., Cornoni-Huntley, J., Locke, B. Z., \& Barbano, H. E. (1987). Longitudinal analyses of psychological wellbeing in a national sample: Stability of means levels. Journal of Gerontology, 42, 50-55. doi:10.1093/geronj/42.1.50

Cudeck, R., \& Harring, J. R. (2007). Analysis of nonlinear patterns of change with random coefficient models. Annual Review of Psychology, 58, 615-637. doi:10.1146/annurev.psych.58.110405.085520

Cudeck, R., \& Klebe, K. J. (2002). Multiphase mixed-effects model for repeated measure data. Psychological Methods, 7, 41-63. doi:10.1037/ 1082-989X.7.1.41

Danner, D. D., Snowdon, D. A., \& Friesen, W. V. (2001). Positive emotions in early life and longevity: Findings from the Nun Study.
Journal of Personality and Social Psychology, 80, 804-813. doi: 10.1037/0022-3514.80.5.804

Diehr, P., Williamson, J., Burke, G. L., \& Psaty, B. M. (2002). The aging and dying processes and the health of older adults. Journal of Clinical Epidemiology, 55, 269-278. doi:10.1016/S0895-4356(01)00462-0

Diener, E., Lucas, R. E., \& Scollon, C. N. (2006). Beyond the hedonic treadmill: Revising the adaptation theory of well-being. American Psychologist, 61, 305-314. doi:10.1037/0003-066X.61.4.305

Diener, E., \& Suh, M. E. (1998). Well-being and age: An international analysis. In K. W. Schaie \& M. P. Lawton (Eds.), Annual review of gerontology and geriatrics (pp. 304-324). New York, NY: Springer.

Femia, E. E., Zarit, S. H., \& Johansson, B. (1997). Predicting change in activities of daily living: A longitudinal study of the oldest old in Sweden. The Journals of Gerontology: Series B: Psychological Sciences and Social Sciences, 52, P294-P302. doi:10.1093/geronb/52B.6.P294

Filipp, S. H. (1996). Motivation and emotion. In J. E. Birren \& K. W. Schaie (Eds.), Handbook of the psychology of aging (4th ed., pp. 218-235). San Diego, CA: Academic Press

Fujita, F., \& Diener, E. (2005). Life satisfaction set point: Stability and change. Journal of Personality and Social Psychology, 88, 158-164. doi:10.1037/0022-3514.88.1.158

Gerstorf, D., \& Ram, N. (2013). Inquiry into terminal decline: Five objectives for future study. The Gerontologist. doi:10.1093/geront/ gnt046

Gerstorf, D., Ram, N., Estabrook, R., Schupp, J., Wagner, G. G., \& Lindenberger, U. (2008). Life satisfaction shows terminal decline in old age: Longitudinal evidence from the German Socio-Economic Pane Study (SOEP). Developmental Psychology, 44, 1148-1159. doi: 10.1037/0012-1649.44.4.1148

Gerstorf, D., Ram, N., Goebel, J., Schupp, J., Lindenberger, U., \& Wagner, G. G. (2010). Where people live and die makes a difference: Individua and geographic disparities in well-being progression at the end of life. Psychology and Aging, 25, 661-676. doi:10.1037/a0019574

Gerstorf, D., Ram, N., Lindenberger, U., \& Smith, J. (2013). Age and time-to-death trajectories of change in indicators of cognitive, sensory, physical, health, social, and self-related functions. Developmental Psychology, 49, 1805-1821. doi:10.1037/a0031340

Gerstorf, D., Ram, N., Mayraz, G., Hidajat, M., Lindenberger, U., Wagner G. G., \& Schupp, J. (2010). Late-life decline in well-being across adulthood in Germany, the United Kingdom, and the United States: Something is seriously wrong at the end of life. Psychology and Aging, 25, 477-485. doi:10.1037/a0017543

Gerstorf, D., Ram, N., Röcke, C., Lindenberger, U., \& Smith, J. (2008) Decline in life satisfaction in old age: Longitudinal evidence for links to distance-to-death. Psychology and Aging, 23, 154-168. doi:10.1037/ 0882-7974.23.1.154

Hall, N. C., Chipperfield, J. G., Heckhausen, J., \& Perry, R. P. (2010). Control striving in older adults with serious health problems: A 9-year longitudinal study of survival, health, and well-being. Psychology and Aging, 25, 432-445. doi:10.1037/a0019278

Hay, E. L., \& Diehl, M. (2010). Reactivity to daily stressors in adulthood The importance of stressor type in characterizing risk factors. Psychology and Aging, 25, 118-131. doi:10.1037/a0018747

Headey, B., Muffels, R., \& Wagner, G. G. (2010). Long-running German panel survey shows that personal and economic choices, not just genes, matter for happiness. PNAS Proceedings of the Academy of Sciences of the United States of America, 107, 17922-17926. doi:10.1073/pnas .1008612107

Heckhausen, J., \& Gerstorf, D. (2011, August). A motivational theory of life-span development: Areas of application in the SOEP. Colloquium presented at the German Institute for Economic Research (DIW), Berlin.

Heckhausen, J., \& Schulz, R. (1995). A life-span theory of control. Psychological Review, 102, 284-304. doi:10.1037/0033-295X.102.2.284 
Heckhausen, J., \& Schulz, R. (1999). The primacy of primary control is a human universal: A reply to Gould's critique of the life-span theory of control. Psychological Review, 106, 605-609. doi:10.1037/0033-295X .106 .3 .605

Heckhausen, J., Wrosch, C., \& Schulz, R. (2010). A motivational theory of life-span development. Psychological Review, 117, 32-60. doi:10.1037/ a0017668

Heckhausen, J., Wrosch, C., \& Schulz, R. (2013). A lines-of-defense model for managing health threats: A review. Gerontology, 59, 438-447. doi: $10.1159 / 000351269$

House, J. S., Kessler, R. C., Herzog, A. R., Meto, R. P., Kinney, A. M., \& Breslow, M. J. (1990). Age, socioeconomic status, and health. Milbank Quarterly, 68, 383-411. doi:10.2307/3350111

Infurna, F. J., Gerstorf, D., Ram, N., Schupp, J., Sprangers, M. A. G., \& Wagner, G. G. (2013). Linking concurrent self-reports and retrospective proxy reports about the last year of life: A prevailing picture of life satisfaction decline. Journals of Gerontology, Series B: Psychological Sciences and Social Sciences. doi:10.1093/geronb/gbt055

Infurna, F. J., Gerstorf, D., Ram, N., Schupp, J., \& Wagner, G. G. (2011). Long-term antecedents and outcomes of perceived control. Psychology and Aging, 26, 559-575. doi:10.1037/a0022890

Infurna, F. J., Gerstorf, D., \& Zarit, S. H. (2011). Examining dynamic links between mastery and health: Longitudinal evidence for differential effects in midlife and old age. Developmental Psychology, 47, 9-18. doi:10.1037/a0021022

Johnson, C. L., \& Barer, B. M. (1997). Life beyond 85 years: The aura of survivorship. New York, NY: Springer.

Juster, R.-P., McEwen, B. S., \& Lupien, S. J. (2010). Allostatic load biomarkers of chronic stress and impact on health and cognition. Neuroscience and Biobehavioral Reviews, 35, 2-16. doi:10.1016/j .neubiorev.2009.10.002

Kleemeier, R. W. (1962). Intellectual change in the senium. Proceedings of the Social Statistics Section of the American Statistical Association, 1, 290-295.

Klein, T. (1996). Determinants of institutionalization in old age. In R. Eisen \& F. Sloan (Eds.), Long-term care: Economic issues and policy solutions (pp. 103-113). Boston, MA: Kluwer. doi:10.1007/978-1-46154096-0_6

Krause, N. (2003). Neighborhoods, health, and well-being in late life. In H.-W. Wahl, R. Scheidt, \& P. Windley (Eds.), Annual review of gerontology and geriatrics (Vol. 23, pp. 223-249). Berlin, Germany: Springer.

Krause, N., \& Shaw, B. A. (2000). Role-specific feelings of control and mortality. Psychology and Aging, 15, 617-626. doi:10.1037/0882-7974 .15.4.617

Kroh, M., Pischner, R., Spieß, M., \& Wagner, G. G. (2008). On the treatment of non-original sample members in the German Household Panel Study (SOEP): Tracing and weighting. Methoden - Daten Analysen, 2, 179-198.

Kroh, M., \& Spieß, M. (2006). Documentation of sample sizes and panel attrition in the Socio Economic Panel (SOEP) (1984 until 2005). DIW Data Documentation No. 15. Berlin, Germany.

Kunz-Ebrecht, S. R., Kirschbaum, C., \& Steptoe, A. (2004). Work stress, socioeconomic status and neuroendocrine activation over the working day. Social Science \& Medicine, 58, 1523-1530. doi:10.1016/S02779536(03)00347-2

Kunzmann, U., Little, T. D., \& Smith, J. (2000). Is age-related stability of well-being a paradox? Cross-sectional and longitudinal evidence from the Berlin Aging Study. Psychology and Aging, 15, 511-526. doi: 10.1037/0882-7974.15.3.511

Lachman, M. E. (2006). Perceived control over age-related declines: Adaptive beliefs and behaviors. Current Directions in Psychological Science, 15, 282-286. doi:10.1111/j.1467-8721.2006.00453.x

Lachman, M. E., \& Firth, K. M. (2004). The adaptive value of feeling in control during midlife. In O. G. Brim, C. D. Ryff, \& R. Kessler (Eds.), How healthy are we? A national study of well-being at midlife (pp. 320-349). Chicago, IL: University of Chicago Press.

Lachman, M. E., \& Weaver, S. L. (1998). The sense of control as a moderator of social class differences in health and well-being. Journal of Personality and Social Psychology, 74, 763-773. doi:10.1037/00223514.74.3.763

Lang, F. R., Featherman, D. L., \& Nesselroade, J. R. (1997). Social self-efficacy and short-term variability in social relationships: The MacArthur Successful Aging Studies. Psychology and Aging, 12, 657-666. doi:10.1037/0882-7974.12.4.657

Lawton, M. P. (1990). Residential environment and self-directedness among older people. American Psychologist, 45, 638-640. doi:10.1037/ 0003-066X.45.5.638

Levenson, H. (1981). Differentiating among internality, powerful others, and chance. In H. M. Lefcourt (Ed.), Research with the locus of control construct (Vol. 1, pp. 15-63). New York, NY: Academic Press. doi: 10.1016/B978-0-12-443201-7.50006-3

Levy, B. R., Slade, M. D., Kunkel, S. R., \& Kasl, S. V. (2002). Longevity increased by positive self-perceptions of aging. Journal of Personality and Social Psychology, 83, 261-270. doi:10.1037/0022-3514.83.2.261

Littell, R. C., Miliken, G. A., Stoup, W. W., \& Wolfinger, R. D. (1996). SAS system for mixed models. Cary, NC: SAS Institute.

Little, R. J. A., \& Rubin, D. B. (1987). Statistical analysis with missing data. New York, NY: Wiley.

Lucas, R. E. (2007). Long-term disability is associated with lasting changes in subjective well-being: Evidence from two nationally representative longitudinal studies. Journal of Personality and Social Psychology, 92, 717-730. doi:10.1037/0022-3514.92.4.717

Lucas, R. E., Clark, A. E., Georgellis, Y., \& Diener, E. (2003). Reexamining adaptation and the set point model of happiness: Reactions to changes in marital status. Journal of Personality and Social Psychology, 84, 527-539. doi:10.1037/0022-3514.84.3.527

Maier, H., \& Smith, J. (1999). Psychological predictors of mortality in old age. The Journals of Gerontology: Series B: Psychological Sciences and Social Sciences, 54, P44-P54. doi:10.1093/geronb/54B.1.P44

McArdle, J. J. (1994). Structural factor analysis experiments with incomplete data. Multivariate Behavioral Research, 29, 409-454. doi 10.1207/s15327906mbr2904_5

Mendes de Leon, C. F., Seeman, T. E., Baker, D. I., Richardson, E. D., \& Tinetti, M. E. (1996). Self-efficacy, physical decline and change in functioning in community-living elders: A prospective study. The Journals of Gerontology: Series B: Psychological Sciences and Social Sciences, 51, S183-S190. doi:10.1093/geronb/51B.4.S183

Mroczek, D. K., \& Kolarz, C. M. (1998). The effect of age on positive and negative affect: A developmental perspective on happiness. Journal of Personality and Social Psychology, 75, 1333-1349. doi:10.1037/00223514.75.5.1333

Mroczek, D. K., Spiro, A., \& Griffin, P. W. (2006). Personality and aging. In J. E. Birren \& K. W. Schaie (Eds.), Handbook of the psychology of aging (6th ed., pp. 363-377). San Diego, CA: Elsevier.

Mroczek, D. K., \& Spiro, A., III. (2005). Change in life satisfaction during adulthood: Findings from the Veterans Affairs Normative Aging Study Journal of Personality and Social Psychology, 88, 189-202. doi: 10.1037/0022-3514.88.1.189

Neupert, S. D., Almeida, D. M., \& Charles, S. T. (2007). Age differences in reactivity to daily stressors: The role of personal control. The Journals of Gerontology: Series B: Psychological Sciences and Social Sciences, 62, P216-P225. doi:10.1093/geronb/62.4.P216

Palgi, Y., Shrira, A., Ben-Ezra, M., Spalter, T., Shmotkin, D., \& Kavé, G. (2010). Delineating terminal change in well-being and subjective health. The Journals of Gerontology: Series B: Psychological Sciences and Social Sciences, 65, 61-64. doi:10.1093/geronb/gbp095 
Pearlin, L. I., \& Schooler, C. (1978). The structure of coping. Journal of Health and Social Behavior, 19, 2-21. doi:10.2307/2136319

Penninx, B. W. J. H., van Tilburg, T., Kriegsman, D. M. W., Deeg, D. J. H., Boeke, A. J. P., \& van Eijk, J. Th. M. (1997). Effects of social support and personal coping resources on mortality in older age: The Longitudinal Aging Study Amsterdam. American Journal of Epidemiology, 146, 510-519. doi:10.1093/oxfordjournals.aje.a009305

Ram, N., \& Grimm, K. J. (2007). Using simple and complex growth models to articulate developmental change: Matching theory to method. International Journal of Behavioral Development, 31, 303-316. doi: 10.1177/0165025407077751

Rodin, J. (1986). Aging and health: Effects of the sense of control. Science, 233, 1271-1276. doi:10.1126/science.3749877

Rowe, J. W., \& Kahn, R. L. (1997). Successful aging. The Gerontologist, 37, 433-440. doi:10.1093/geront/37.4.433

Ryff, C. D., \& Singer, B. (1998). The contours of positive human health. Psychological Inquiry, 9, 1-28. doi:10.1207/s15327965pli0901_1

Schilling, O. (2006). Development of life satisfaction in old age: Another view on the paradox. Social Indicators Research, 75, 241-271. doi: 10.1007/s11205-004-5297-2

Schilling, O. K., Wahl, H.-W., \& Wiegering, S. (2012). Affective development in advanced old age: Analyses of terminal change in positive and negative affect. Developmental Psychology. doi:10.1037/a0028775

Schimmack, U., Schupp, J., \& Wagner, G. G. (2008). The influence of environment and personality on the affective and cognitive component of subjective well-being. Social Indicators Research, 89, 41-60. doi: 10.1007/s11205-007-9230-3

Seeman, T. E., Unger, J. B., McAvay, G., \& Mendes de Leon, C. F. (1999). Self-efficacy beliefs and perceived declines in functional ability: MacArthur Studies of Successful Aging. The Journals of Gerontology: Series B: Psychological Sciences and Social Sciences, 54, P214-P222. doi:10.1093/geronb/54B.4.P214

Singer, J. D., \& Willett, J. B. (2003). Applied longitudinal data analysis: Modeling change and event occurrence. New York, NY: Oxford University Press. doi:10.1093/acprof:oso/9780195152968.001.0001

Skaff, M. M. (2007). Sense of control and health: A dynamic duo in the aging process. In C. M. Aldwin, C. L. Park, \& A. Spiro (Eds.), Handbook of health psychology and aging (pp. 186-209). New York, NY: Guilford Press.

Surtees, P. G., Wainwright, N. W. J., Luben, R., Khaw, K.-T., \& Day, N. E. (2006). Mastery, sense of coherence, and mortality: Evidence of independent associations from the EPIC-Norfolk Prospective Cohort Study Health Psychology, 25, 102-110. doi:10.1037/0278-6133.25.1.102

Surtees, P. G., Wainwright, W. J., Luben, R., Wareham, N. J., Bingham, S., \& Khaw, K.-T. (2010). Mastery is associated with cardiovascular disease mortality in men and women at apparently low risk. Health Psychology, 29, 412-420. doi:10.1037/a0019432

Uchino, B. N. (2006). Social support and health: A review of physiological processes potentially underlying links to disease outcomes. Journal of Behavioral Medicine, 29, 377-387. doi:10.1007/s10865-006-9056-5

Verbrugge, L. M., \& Jette, A. M. (1994). The disablement process. Social Science \& Medicine, 38, 1-14. doi:10.1016/0277-9536(94)90294-1

Vogel, N., Schilling, O. K., Wahl, H.-W., Beekman, A. T. F., \& Penninx, B. W. J. H. (2012). Time-to-death-related change in positive and negative affect among older adults approaching the end of life. Psychology and Aging. doi:10.1037/a0030471

Wagner, G. G., Frick, J. R., \& Schupp, J. (2007). Enhancing the power of household panel studies: The case of the German Socio-Economic Panel Study (SOEP). Schmollers Jahrbuch, 127, 139-169.

White, S. M., Wójcicki, T. R., \& McAuley, E. (2012). Social cognitive influences on physical activity behavior in middle-aged and older adults. The Journals of Gerontology: Series B: Psychological Sciences and Social Sciences, 67, P18-P26. doi:10.1093/geronb/gbr064

Winter, D. G., John, O. P., Stewart, A. J., Klohnen, E. C., \& Duncan, L. E. (1998). Traits and motives: Toward an integration of two traditions in personality research. Psychological Review, 105, 230-250. doi:10.1037/ 0033-295X.105.2.230

Received December 30, 2013

Revision received April 30, 2014

Accepted May 12, 2014 